\title{
Service Quality Strategy Challenges for Managers and Frontline Employees in the South African Post Office in the North West Province
}

\author{
Elsie Mbua Eposi ${ }^{1} \&$ Marius Potgieter ${ }^{1}$ \\ ${ }^{1}$ School of Management Sciences, North-West University, South Africa \\ Correspondence: Elsie Mbua Eposi, School of Management Sciences, North-West University, South Africa.
}

Received: June 29, 2021

Accepted: August 5, 2021

Online Published: August 19, 2021

doi:10.5430/ijfr.v12n5p89

URL: https://doi.org/10.5430/ijfr.v12n5p89

\begin{abstract}
This paper addresses the possible factors that hamper service quality strategy implementation by managers and frontline employees and thus hindering consumer satisfaction with the South Africa Post Office (SAPO) in the North West province of South Africa. This study was grounded on the contingency theory which emphasises the need for management, managers and frontline employees to utilise various methods for resolving problems that may obstruct strategy implementation. This study adopted a qualitative research approach with semi-structured interviews to obtain data from selected participants. Data was collected from three post office branch managers, one area manager and ten frontline employees, making a total of fourteen participants and the data were analysed using Atlas-ti (Version 8.1). The results obtained indicate that post offices struggle to implement their specific strategies due to factors such as vision barrier, management barrier, resource barrier, issues with organisational leadership and commitment, lack of proper implementation of plans, inability to communicate effectively as a challenge to strategy implementation, technological barriers as a challenge to strategy implementation and culture, environment, and change management. The study recommends that post offices should allocate adequate resource and funding during the implementation process and deploy skilled personnel to improve strategy implementation. It is further recommended that managers consider strategy implementation as a priority, as well as the need to include frontline employees as part of strategic planning. Effective collaboration with management, managers and frontline employees, high leadership commitment, improved technological advancement and considering the environmental factors will improve high service quality. All this is in an endeavour to facilitate strategy implementation to accomplish reasonable service delivery to all postal consumers in South Africa.
\end{abstract}

Keywords: strategic management, strategic implementation, post offices, managers, frontline employees, postal consumers

\section{Introduction}

Businesses, such as the postal sector, need to monitor their internal and external business environments to effect change in their business and service processes. To pledge change in a commercial environment, there is a need to implement strategic management to accomplish the desired purposes of an organisation. In order to initiate transformation in an organisation, there is a need to implement the aims of strategic management, and its implementation to achieve anticipated objectives. In terms of strategic management, several authors such as Mapetere et al. (2012), Meyer (2012) and Ohaegbu and Awele (2015) and Meyer (2016), consider strategic management as the most critical and fundamental process for public sector organisations in achieving their desired outcomes. However, Jelenc (2009) claimed that the central part of effective strategic management is judged as a proper integration of strategy formulation and strategy implementation. Ackermann and Eden (2013) explain that strategic management is a collection of the ongoing activities of strategic analysis, strategy creation, implementation, and monitoring. It is also the art and science of formulating, implementing, analysing, and evaluating cross-functional decisions that enable an organisation to achieve its objectives (Verweir, 2014). Afonina (2015) describes strategic management as a management process by which future goals of change are determined and current decisions to actualize a specific objective are decided upon. Strategic management is widely acknowledged as an ongoing process of shaping the future of the public sector, such as the South African Post Office (SAPO). Ansoff et al. (2018) emphasize that strategic management should be results-oriented and should, thus, focus on results not currently achieved by the actions of an organisation's rivals through the process of strategic management. 
Strategic management, and its implementation are important tools for an organisation for its future development and for maintaining competitiveness. Mathore (2016) affirms that strategic implementation dictates that an organisation set annual objectives, comes up with policies, motivates staff, and allocates adequate resources to enable the execution of formulated strategies. In South African organisations, strategy implementation is more important than strategy formulation and the ability to implement a strategy is more important than the ability to formulate a strategy (Jooste \& Fourie, 2009). A poor understanding of strategy by the workforce, ineffective communication of the strategy to the workforce, and that strategic leadership is not perceived to be a major barrier to effective strategy implementation are the most important barriers to effective strategy implementation. These challenges differ across organisations in South Africa and in the case of SAPO, the challenges are not known. It is postulated that the main reason for the failure of the strategic plan is a lack of appropriate models and frameworks to guide management and staff who are involved in the implementation of the strategic plan in well-known organisations (Alexander, 1991). How true this statement is with regards to SAPO is yet to be established.

Irrespective of operative, and improvement of postal sectors in South Africa, records indicate that post offices perform below expectations in providing adequate services to postal consumers as stipulated in the mission and vision statements of SAPO (SAPO, 2014). SAPO and other concerned authors in South Africa have conducted several studies on measures to improve the declining mail volume, and the declining number of postal consumers and revenue, and to address the problems surrounding the low performance of post offices in terms of service quality. The inability of post offices to achieve their high service quality objective led to the 2014 national strike and the loss of R1billion of its revenue, due to consumers switching to other options. Post office clients reported on the uncourteous attitude of some staff, delays in receiving mail, wrong distribution of mail, inability to enforce decisions, delays in responding to consumer complaints, and the unwelcoming atmosphere of some of the post offices, especially at counter level (SAPO, 2014). This can be ascribed to strategic leaders in South African Post Offices not possessing the required strategic leadership capabilities to turn the circumstances around. With respect to the failure of public sectors, especially post offices, to achieve their specified strategies, this study investigates the challenges in SAPO strategy implementation that result in poor service quality to postal consumers in the North West province in South Africa.

\section{Problem Identification}

According to the SAPO Annual Report (2015/2016) and the SAPO Corporate Plan (2018/19-2020/), post offices are faced with serious challenges with regard to massive service delivery, such as strategic issues, decline in revenue, loss of consumers, decline in mail volume, staff shortages, poor work ethics, infrastructure, materials and equipment. Problematic service quality emanates from poor employee attitude, poor expertise, and poor work ethics, as mentioned by Musikavanhu (2017). The above challenges caused a high decline in postal services due to the poor performance of post offices, which has resulted in a high decline in postal consumers. The recommendations from these reports indicate that post offices in South Africa should formulate soluble measures to moderate these issues. Despite the recommendations proposed, it has been a challenge for post offices to identify the need to assess the reality of poor postal performance within the postal sectors of South Africa.

It is evident that progress has been made in the postal sector with regards to service delivery as SAPO operations have begun to stabilise since the 2016/17 financial year. This is evident in the improvement in the delivery standard for letters, from $69.22 \%$ in the $2014 / 15$ financial year to $77.69 \%$ in the $2017 / 18$ financial year (SAPO Corporate Plan 2018/19-2020/). However, there is also a need to deliver equitable services to all postal consumers in South Africa as stipulated by policy. This is still a far fetch dream. Service quality challenges which contribute to the main problems in the postal sector have been attributed to the inability of post offices to implement approved strategies, extend the postal network, and limited postal resources (SAPO Strategic Plan, 2019/20-2021/22). This problem persists and does not receive the urgent attention it deserves due to negligent strategy implementation practices. The situation is however understood since strategy implementation is the most difficult stage of strategic management and requires a series of carefully interrelated activities that could enable public concerns to achieve their goals (Joyce, 2017). As such, it is posited that post offices in South Africa are not performing exceedingly well in strategy implementation. Olson (2017) affirms that postal managers are expected to clearly state the vision, mission, and value statements which should be supported by reasonable action to achieve the objectives of their postal branches. However, the challenges managers face in the implementation process is unknown. As such, poor service quality by SAPO in the North West province could arguably be linked to strategy implementation failure. This study was motivated by this uncertainty, as well as, investigating the key enablers of successful strategy implementation. This is in an endeavour to achieve reasonable service quality for all postal consumers in South Africa. 


\section{Theoretical Framework}

This study is grounded on the Contingency Theory of Leadership, as depicted in Figure 1,-, together with the external environmental forces that influence organisational performance.

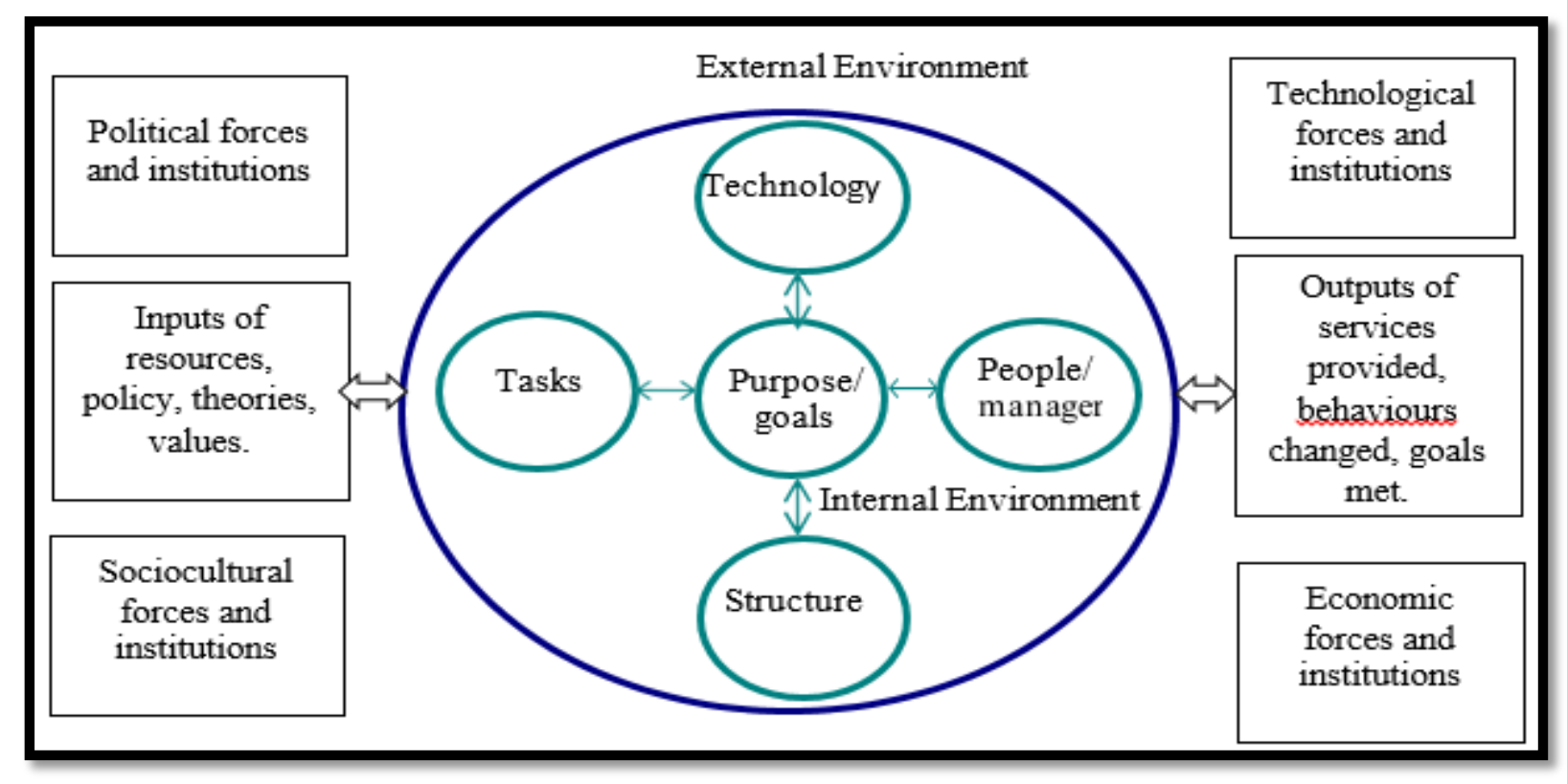

Figure 1. Contingency Theory of Leadership Model

Source: Schoech (2006)

\subsection{Contingency Theory of Leadership}

Figure 1 above depicts the external environmental forces as political, technological, economic, and sociocultural external forces interacting with the internal organisational variables (technology, people, structure, tasks) and these are coordinated by management to achieve desired goals. The Contingency Theory of Leadership is based on the premise that managers should consider the contingent of the external and the internal environmental forces in order to make satisfactory decisions for the organisation, which are aimed at achieving a unitary goal. Contingency or the situation theory, as propounded by Fredler (2015), stresses the significance of using diverse approaches to resolve issues that may arise in an organisation (Sauser et al., 2009). Flynn et al. (2009) and Ahimbisibwe et al. (2015) posit that management should use different approaches to address different situations. The contingency concept implies that organisations should interact continuously with the internal and external environment, thereby receiving feedback and also developing adaptive features to overcome challenges that may arise as circumstances change (Ndolloh, 2016). Hellriegel et al. (2016) affirm that the contingency theory suggests that management should make their decisions based on the present situation as per the surrounding environment. In this respect, it is important to note that different situations may require different problem resolving mechanisms. Organisations need to scan the external environment to identify the most suitable problem resolving mechanisms at their disposal.

South Africa's post offices need to adopt the contingency approach in the strategic management of their service quality. Management needs to communicate adequately with consumers to understand their challenges to thereby identifying views and difficulties arising in their service delivery and devising strategies to resolve it in order to aim for service excellence. The contingency of leadership model establishes that a leader's behaviour (SAPO in this case) should be directive, supportive, participative, and achievement-oriented to ensure goal actualisation and performance. The model further depicts that management should combine the task and relationship motivated styles with situation controlling capacities in order to ensure effective work performance or output (Shu, 2015).

In this case, the theory encourages capacity building in post offices, technical support in service delivery, socio-economic support with consumers, and it encourages collaboration between post office managers, frontline 
employers, and postal consumers to enhance service delivery. It further supports post offices to interact with its consumers, thereby understanding the problems affecting postal services, thus identifying potential solutions to enhance service quality.

\section{Conceptual Framework}

Subsequently is an exposition of literature on strategic management as recorded by management scholars.

\subsection{Understanding Strategic Management}

Businesses, such as post offices, need to monitor their internal and external business environments to effect change in their business and service processes. To pledge change in a commercial environment, there is a need to implement strategic management to accomplish the desired purposes of an organisation. This section presents an overview of strategic management as professed by several scholars in this field of study. Looking at strategic management from a survival and growth angle, Strydom (2015) regards it as the process of determining how to reach an organisation's long-term goals with the resources expected to be available. This involves the major strategic issues of the organisation and that it ought to meet certain criteria which include the relationship between the organisation and its external environment and the involvement of the organisation in decision-making. Strategic management concentrates on the fate, survival, and growth of an organisation and its management should actively be involved in advancing positive organisational change toward quality and quality assurance. As explained above, strategic management is widely acknowledged as an ongoing process of shaping the future of organisations and that of the public sector, such as that of SAPO. Ansoff et al. (2016) emphasize that strategic management should be results-oriented and should, thus, focus on results not currently achieved by the actions of an organisation's rivals through the process of strategic management. By implication, SAPO's strategy is deemed meaningless until it is implemented to meet high service quality and consumer satisfaction. Thus, the ensuing section expounds on strategic implementation.

\subsubsection{Strategic Implementation}

Strategic management, the formulation of the strategy and its implementation, are important tools of an organisation for its future development and for maintaining competitiveness. Mathore (2016) specifically stated that strategy implementation dictates that an organisation devise annual objectives, comes up with policies, motivates staff, and allocates adequate resources to enable the execution of the formulated strategies. This involves developing a culture that supports strategy, forming an effective organisational structure, readdressing marketing forces, preparing budgets, developing and making use of information systems, and associating staff compensation to organisational performance (Sikora \& Ferris, 2014; Bryson et al., 2018).

Thus, for SAPO to effectively implement its strategic plan, there is the need for a purposeful strategic plan and postal policies that are effective and easy to implement. Also, management needs to provide staff with adequate resources for them to deliver quality services to their consumers. In addition, management is to provide incentives and training programs to motivate staff to reach targeted performance. It is important for management to encourage managers and frontline employees to support the organisational culture and structures, and its strategy in order to counter the decline in mail, revenue, and number of consumers and strategic issue that affect high service quality to be delivery to postal consumers.

The management of an organisation depends largely on strategy implementation. This offers a road map for how an organisation should be run to achieve its mission, vision, and strategic goals (Bamberger et al., 2014: Jenkins \& Williamson, 2015). The application of strategies has crossed the normal norm of their applicability in the profit-making organisation to even those that are not geared towards profits. Christian religious institutions find strategic management applicability vital to their operations, which is a deviation from their normal way of solving their operational shortcomings (Ndung'u, 2016). According to Njihia (2009) and Baum et al. (2016), organisations that have been applying strategies (for example the Porters and Ansoffs strategies) have been performing in exemplary ways as compared to those that have not been applying strategies. Maroa and Muturi (2015) found that $90 \%$ of well-formulated strategies fail at the implementation stage and only $10 \%$ of formulated strategies are successfully implemented. The successful implementation of strategy is fully dependent on the involvement of all the participants in an organisation. Communicating the progress of implementing the strategy to the stakeholders assists them in determining whether corrective action is required (Pearce \& Robinson, 2013; Klettner, 2014; Maroa \& Muturi, 2015). By implication, the challenges in SAPO could be as a result of poor communication of its strategic plan to managers and frontline employees. Thus, the need for SAPO to communicate their strategic plan effectively and efficiently in order to improve service quality. 
Strategy implementation has become a key focus for organisations and continues to attract attention as it plays a key role in the success of organisations on a worldwide scale. Johnsons and Scholes (2008) and Bryson (2018) suggested that in knowledge-based economies, people are truly the most valuable asset which human resources policies need to reflect. Johnson and Scholes (2008) noted that strategy implementation is the translation of strategy into action. It entails the institutionalization and operationalization of strategies and managing ensuing change. Thus, for SAPO to successfully implement its strategic plan effectively, requires visible leaders who passionately carry and communicate the vision in a manner that influences employee's behaviour towards attaining this vision. SAPO's top management needs to encourage a participative strategy implementation process to achieve superior performance and this should lead to service quality.

\subsection{Reasons for the Failure of Strategy Implementation in the Public Service}

Due to the incapability of post offices in South Africa to implement their strategies rightfully in order to achieve effective service delivery, this paper investigates the set of factors identified by several authors that could inhibit the strategy implementation processes. Table 1 presents a compendium of the factors identified by various scholars that impede strategy implementation.

Table 1. Concept-analysis of factors that negatively affect strategy management implementation

\begin{tabular}{|c|c|c|c|c|c|c|c|c|c|c|}
\hline $\begin{array}{l}\mathscr{U} \\
\vdots \\
\ddot{0}\end{array}$ & 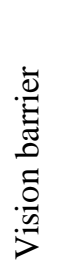 & 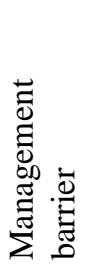 & 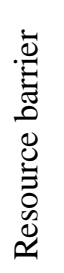 & 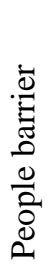 & 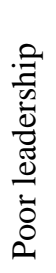 & 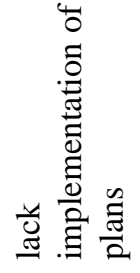 & 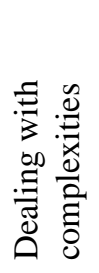 & 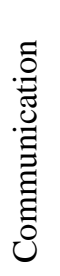 & 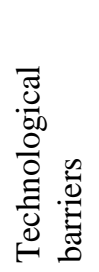 & 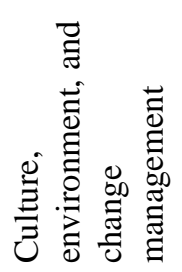 \\
\hline $\begin{array}{l}\text { O'Donnel \& Boyle } \\
(2008)\end{array}$ & $\sqrt{ }$ & $\sqrt{ }$ & $\sqrt{ }$ & $\sqrt{ }$ & & & $\sqrt{ }$ & $\sqrt{ }$ & $\sqrt{ }$ & $\sqrt{ }$ \\
\hline $\begin{array}{l}\text { Kaplan \& Norton } \\
\text { (2008) }\end{array}$ & $\sqrt{ }$ & & & & & & & & & \\
\hline Jonesl (2010) & & & & & $\sqrt{ }$ & & & & & \\
\hline $\begin{array}{l}\text { Ehlers \& Lazenby } \\
(2010)\end{array}$ & $\sqrt{ }$ & & & & $\sqrt{ }$ & & & & $\sqrt{ }$ & $\sqrt{ }$ \\
\hline DuBrin (2011) & & $\sqrt{ }$ & & & & & $\sqrt{ }$ & $\sqrt{ }$ & & \\
\hline Kotter (2012) & $\sqrt{ }$ & & & & & & $\sqrt{ }$ & $\sqrt{ }$ & & \\
\hline Beer (2013) & & & $\sqrt{ }$ & & & & $\sqrt{ }$ & $\sqrt{ }$ & & \\
\hline $\begin{array}{l}\text { Barton \& Ambrosini } \\
\text { (2013) }\end{array}$ & & $\sqrt{ }$ & & $\sqrt{ }$ & & & $\sqrt{ }$ & $\sqrt{ }$ & & \\
\hline Thornton (2013) & & & & $\sqrt{ }$ & & & $\sqrt{ }$ & $\sqrt{ }$ & & \\
\hline Miller et al. (2013) & & & $\sqrt{ }$ & & & & & & $\sqrt{ }$ & $\sqrt{ }$ \\
\hline $\begin{array}{l}\text { Eustace \& Martins } \\
\text { (2014) }\end{array}$ & $\sqrt{ }$ & & & & $\sqrt{ }$ & $\sqrt{ }$ & & & & \\
\hline Rajasekar (2014) & & & & & $\sqrt{ }$ & $\sqrt{ }$ & & & $\sqrt{ }$ & $\sqrt{ }$ \\
\hline Ungerer et al. (2015) & & & & & $\sqrt{ }$ & $\sqrt{ }$ & & & $\sqrt{ }$ & $\sqrt{ }$ \\
\hline $\begin{array}{l}\text { Siddique \& Shadbolt } \\
(2016)\end{array}$ & & $\sqrt{ }$ & & & $\sqrt{ }$ & $\sqrt{ }$ & & & & \\
\hline Gime (2016) & & & $\sqrt{ }$ & & $\sqrt{ }$ & $\sqrt{ }$ & & & & \\
\hline Yuen \& Lim (2016) & & & $\sqrt{ }$ & & & & & & $\sqrt{ }$ & $\sqrt{ }$ \\
\hline Olson (2017) & & & $\sqrt{ }$ & & $\sqrt{ }$ & $\sqrt{ }$ & & & $\sqrt{ }$ & $\sqrt{ }$ \\
\hline
\end{tabular}

Kaplan and Norton (2008) explain that 'organisational failure might occur due to a lack of strategy definition by top management to efficiently administer their operations, as there is a lack of integration between practices while an all-inclusive management system is deemed lacking. The four most mentioned barriers contribing towards failure in strategy implementation are, as illustrated in Figure 2: vision, management, resources, and people barriers. 


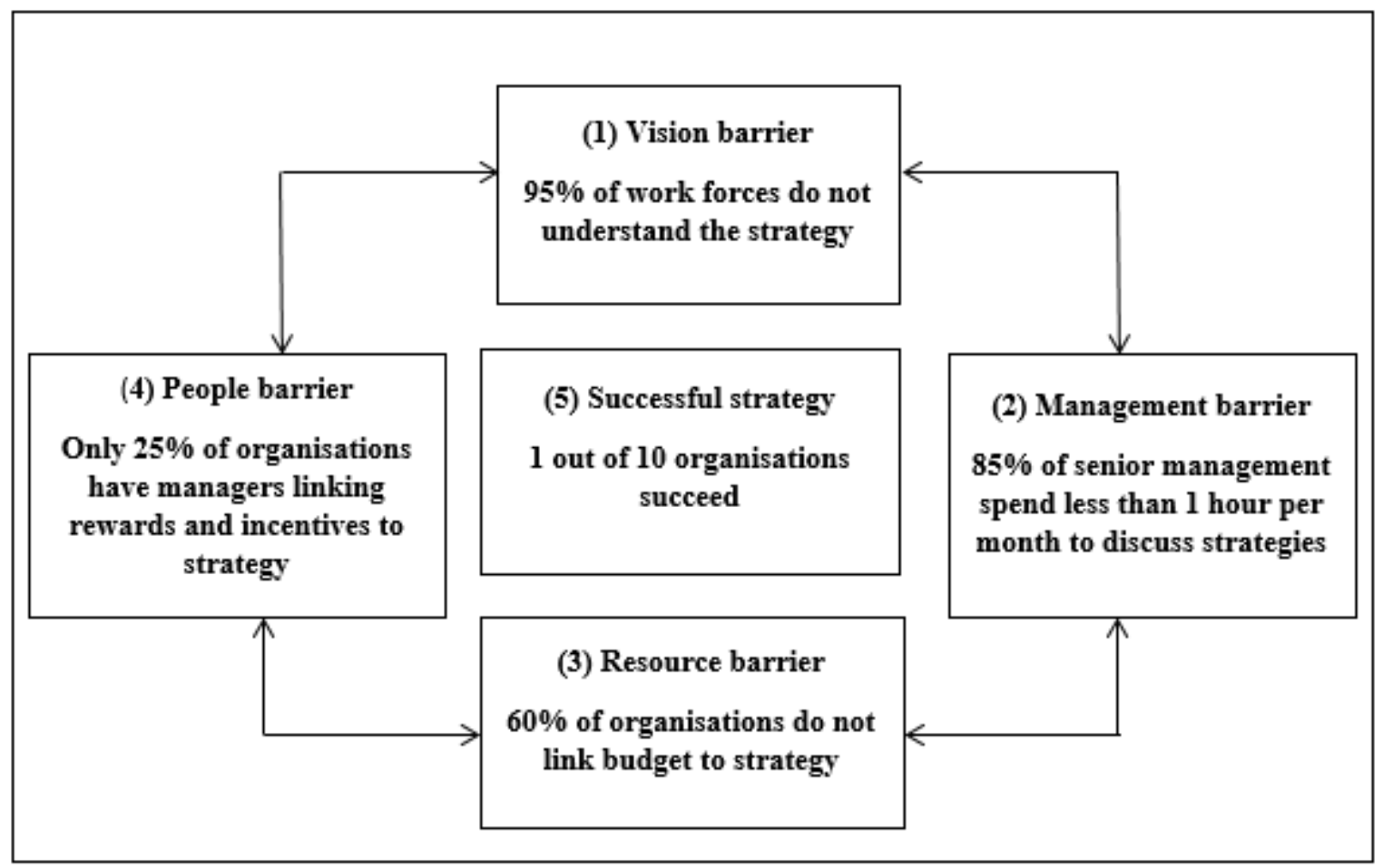

Figure 2. Strategy implementation failure

Source: Kaplan and Norton (2008)

The subsequent section explicates on the barriers indicated in Table 1 and Figure 2.

\subsubsection{Vision Barrier}

The organisational vision refers to a statement that encapsulates the core beliefs and values of an organisation. A vision barrier is created when many of the employees do not comprehend the specified approach of the organisation, which leads to an inability to follow the strategic direction of the organisation (Ehlers \& Lazenby, 2010). As indicated in Figure 2, the barrier that exists when 95\% of the workforce does not understand the strategic vision of the organisation. In this regard, Kaplan and Norton (2008) and Ehlers and Lazenby (2010) opine that a vision statement should be inspirational in guiding employees in achieving organisational objectives. Vision statements are difficult to initiate as there is a wide gap between paperwork and the daily actions of employees, and management should devise ways to educate employees on the vision and strategic goals of the organisation, so that all employees take ownership of such vision. From this discussion, if the SAPO vision statement is not communicated or implemented correctly, then the organisation cannot translate its strategy into action. Thus, an effective SAPO vision statement would contribute towards moving the SAPO strategic planning process from the present to the future. Thus, leading towards high service performance and long-term customer's satisfaction.

\subsubsection{Management Barrier}

Even though managers view strategy implementation as a top management activity, many managers do not meet the strategic goals set by their organisations. It is observable in Figure 2 that as high as $85 \%$ of senior management do not spend quality time discussing matters related to organisational strategies and strategy implementation (Kaplan \& Norton, 2008). Management, according to DuBrin (2011), is regarded as the attainment of organisational goals efficiently and effectively by planning, organising, coordinating, directing, and leading. Managers are expected to devote time discussing these elements of management and implementing the objectives of strategic management to ensure that the objectives of the organisation are achieved. To achieve the desired goals in a postal context, post office role players should endeavour to discuss organisational strategies and strategy implementation with all members of top management so that detailed duties are assigned to specific individuals who should be held accountable. By implication, SAPO need to implement an effective managerial strategic plan that will give managers 
opportunities to develop high managerial skill that will lead to high levels of service quality.

\subsubsection{Resource Barrier}

Organisational resources, such as human and financial, should, according to Yuen and Lim (2016), be placed correctly within an organisation for the attainment of organisational growth. This proposition, according to Kaplan and Norton (2008) and Knott (2016), entails that management should examine the competencies of employees before allocating them to specific duties, in order not to waste talent and resources. It is observable in Figure 2 that $60 \%$ of organisations do not align their budgets with their strategy. This signifies that financial resources are not optimally utilised and by extension many resources are wasted or are incorrectly channeled towards unprofitable ventures that do not yield positive results, or which are not indicated in the strategic goals of an organisation. In this regard, poor resource allocation and the management thereof are viewed as a significant barrier to strategy implementation (Yuen $\&$ Lim, 2016). In this case, SAPO management should ensure that the right resources are employed, and they should also ensure that the available resources are channeled into positive investments as this could result in the proper implementation of their strategies. Thus, the availability of sufficient resources allocated to the functional units of SAPO could lead to high service quality, as well as high customer satisfaction.

\subsubsection{People Barrier}

The fact that management is disinclined to dedicate adequate time to discussing issues related to strategy implementation invariably leads to the under-provision of incentives for strategy execution (Ehlers \& Lazenby, 2010). Figure 2 depicts that up to $75 \%$ of incentives are not linked to strategy execution. This is also caused by management's inability to work as a team in strategy execution (Barton \& Ambrosini, 2013). Thanyawatpornkul et al. (2016) affirm that incentives tend not to be linked to strategy execution. This is also caused by management's inability to work as a team in strategy execution (Barton \& Ambrosini, 2013; Jarzabkowski \& Kaplan, 2015). Strategy implementation is made difficult because of the inherent resistance to change and management issues in organisations. Management is expected to reach a consensus on the actual path to follow in implementing strategy effectively and timeously. Management should thus constantly review its strategies and make necessary adjustments to guarantee success (Hornstein, 2015). In a situation where management fails to implement necessary measures to strengthen the capacity of the organisation, Barton and Ambrosini (2013) postulate that this is known as the 'people barrier' to strategy implementation. Jones and Hill (2014) affirm that the involvement of lower-level management in the success of strategy implementation is important, particularly in today's technology drive era where imminent success is often based on 'luck and chance discoveries rather than on rational strategy. In this case, an engaged employee is aware of the business context and works with colleagues to improve performance for the benefit of the organisation. Thus, SAPO management must work to develop and nurture engagement, which requires a two-way relationship between employer and employee. In order to accomplish the anticipated goals in a postal context, management should endeavour to discuss organisational strategies and strategy implementation with managers and frontline employees to ensure that detailed responsibilities are allocated to specific persons. Apart from the barriers to effective strategy execution as illustrated in Figure 2, there are five other factors proposed by literature that also pose barriers to strategy implementation and these are now being dealt with in more detail.

\subsubsection{Issues With Organisational Leadership and Commitment}

Poor leadership, according to Rajasekar (2014), is among the factors that cause the failure of strategy implementation. There is a need for managers to guide and control the nature of activities in an organisation. Girma (2016) affirms that logical action and good decisions by top management in the process of strategy implementation enable an organisation to achieve its objectives. It requires that top management should adhere to the norms, policies, and rules of the organisation while they constantly communicate with employees, to keep them on the right track (Eustace \& Martins, 2014). Organisational leaders should learn how to appreciate and nurture talent, build trust, develop close ties between employees, confront challenges, and communicate satisfactorily with employees (Mitchell, 2015). Leaders are expected to develop managerial competency in an organisation by developing employees' skills, time management skills, decision-making capabilities, and accuracy in goal attainment. The greatest tasks of leaders are to motivate employees during the work process, to manage stakeholders in the business environment, to set attainable goals, to clarify tasks, and to delegate authority to ensure that strategy implementation is successful (Mitchell, 2015). In this case. SAPO leaders ought to be able to take control of the organisational situation to ensure that nobody defies the rules of operation in the company. SAPO needs to undertake a situation analysis to determine its strengths and weaknesses. It needs to maximize strengths and avoid/eliminate weaknesses. Also, SAPO management has to ensure that the rest of the organisation is committed to the strategy, by convincing employees that the strategy is important and management also needs to create a meaning of strategy so that employees accept and support the strategy, and if 
that is done then it will undoubtedly lead to effective productivity and high service satisfaction.

\subsubsection{Lack of Proper Implementation of Plans}

Managers are expected to state clearly the vision, mission, and value statement of the organisation, which should be supported by reasonable action to achieve the stated objectives (Olson, 2017). The implementation of strategic plans needs to be clear, while managers are required to communicate reviews and agreements on contingencies with employees (Kaplan \& Norton, 2008). The inability to implement plans as agreed upon by top management can, however, obstruct or delay the efficient implementation of strategies. The following process, as recommended by Brinkschroder (2014) and Olson (2008), should guide strategy implementation:

- Management should decide on a strategic plan after agreeing with all stakeholders involved in the strategy implementation process.

- Organisational budgets should be well aligned with annual goals, which ought to be based on specific financial estimates.

- Management should assign responsibilities to different groups of stakeholders.

- A scorecard should be available for tracking and monitoring all plans.

- Management should establish a performance management system to measure the performance of employees and all stakeholders involved.

- The totality of plans should be communicated to stakeholders.

- Weekly or monthly meetings should be held based on strategy implementation reporting and monitoring.

- Management should set up review dates at which time the line strategic plans should be reported, deliberated, and reviewed.

In this case, SAPO needs a successful strategy implementation plan, which means every person in the organisation works together and contributes to the effort of strategy implementation. Thus, successful strategy implementation will lead towards better organisation performance, as well as service quality.

\subsubsection{Inability to Communicate Effectively as a Challenge to Strategy Implementation}

Communication is the procedure of passing information from a sender to a receiver and from a receiver to a sender through a chosen medium (Wells, 2011). Koschmann (2012) postulates that organisational communication involves the employees and/or stakeholders of an organisation exchanging information within and outside their business environments. To effectively implement organisational strategies, communication should flow among the stakeholders of an organisation. Beer (2013) advocates that the effective communication of strategies in an organisation contributes towards the efficient execution of strategies. Furthermore, in the event of managers not being able to communicate organisational strategies to employees in such a way that all will comprehend it could inhibit the implementation of strategy. Barrick et al. (2015) confirm that employees do not necessarily understand the organisational strategy, and this then hinders strategies from being implemented and could cause the organisation to lack possible vision. In this case, having clear and effective communication should be seen as one of the main contributors for dealing with strategy implementation challenges.

\subsubsection{Technological Barriers as a Challenge to Strategy Implementation}

The concept of technology refers to the scientific application of machinery and other devices to the work process to achieve the purpose of an organisation (Marx, 2010; Wahab et al., 2012). Because technology is considered a solution to some problems in an organisation, management should be creative in ensuring that it is applied competently to achieve the goals of the organisation. Some organisations (and post offices) do not provide enabling technological advancement, which inhibits the implementation of their strategic goals. According to the Auditor-General's (2017) report, South Africa struggles to provide and maintain infrastructure to enable industrial, commercial, and household sectors to function effectively. Therefore, organisations (or post offices in this case) need to invest in a strong network of technology that is designed to support the implementation of the organisation's strategic objectives. The implementation of effective technology will lead towards delivering quality customers service that will enable SAPO to obtain and maintain a competitive edge in the market, and to increase not only their customer numbers but also their revenue.

\subsubsection{Culture, Environment, and Change Management}

Culture refers to a set of standard characteristics and a common form of knowledge, behaviour, and understanding 
adopted by people living in a given community, and these are dispersed through socialisation (Zimmermann, 2015). In the same vein, O'Donnel and Boyle (2008) posit that organisational culture is intertwined with culture as it deals with the practices organisations adopt for handling people and business processes.

To implement a strategy in an organisation, Ehlers and Lazenby (2010) assert that there is a need for change management, which includes the organisation's implementation of diverse strategies to move from a current state to a higher level. Ehlers and Lazenby (2010) and Siddique and Shadbolt (2016) concur that the implementation of strategic management in organisations requires active leadership that is liable to convert the input into output. In this respect, O'Donnel and Boyle (2008) acknowledged that the implementation of the strategic management process requires managers to create an appropriate environment for change, and managers who position themselves as champions who adopt employee engagement and empowerment, employ team orientation, assessment of change, and train employees.

In the business environment, in the views of Pollack and Pollack (2015), organisations would not need to be too concerned regarding threats from the external environment if their change processes have been adequately planned for. Miller et al. (2013) noted that change is determined by cultural heritage and that employees could be influenced to adapt or change their behaviour, which leads to organisational culture. Managers are expected to establish a culture that enables the implementation of strategic management to move the organisation forward. In the absence of creating a favourable environment for change, Ehlers and Lazenby (2010) and Cândido and Santos (2015) concur that the implementation of organisational strategies would not be possible.

The above discussion dealt with additional reasons for failure in the implementation of organisational strategy. It must be noted that management can make progress in the implementation of strategy if these factors are considered (Rouleau \& Balogun, 2011; Radomska, 2015). In this case, SAPO management should establish an effective organisational culture that would enable the implementation of strategic management to move the organisation forward and to improve its customers market and consumer demand.

\section{Research Methodology}

This study adopted an interpretive paradigm, which maintains that interpretivism, usually a qualitative approach, arises from the understanding that the study of humans is different to that of natural sciences and focuses on knowledge and views of the situation being studied (Goldkhul, 2012). Concurring with Neumann (2014), who argues that the interpretivism paradigm maintains that the subject matter examined by the natural sciences is different from that of the social sciences. Moreover, all participants have their distinctive interpretations of reality and the research can develop and enquire about their attitudes, beliefs and values and focus on bringing about meaning and knowledge (Rahi, 2017). These principles are particularly important in ethnographic methodology and lean towards a social constructivist approach generating meaning and knowledge (Neumann, 2014). Interpretivist research methods include interviews and research that makes provision for variables to be documented.

This study adopted a qualitative approach by studying several documents and face-to-face interviews aimed at finding solutions to the research problem of the study. The study adopted face-to-face interviews with three branch managers, one area manager and ten frontline employees in the South Africa Post Offices to collect data on strategy implementation towards achieving service quality. The importance of face-to-face interviews is that it enables cooperation of participants and in turns ensures a high response rate (Maree, 2010). Post office managers and frontline employees were selected purposively due to their vast experience in strategy implementation towards achieving service quality at their various post offices. An interview guide was developed and focused on the challenges to strategy implementation and to improve service quality. A set of predetermined open-ended questions were formulated to gain relevant data from the participants. The questions were communicated in English in order to enhance easy understanding and the interviews were conducted by the researcher and two assistants who were well coached beforehand. The interviews took 15 to 20 minutes and the individual interviews were conducted when the participants were available, either before service or after service times. For consistency purposes, the asking of questions was done in the same manner and same order. Data were analysed using Atlas-ti version 8.1. Also, the necessary ethical concepts of research such as informed consent to participate in the study, voluntary participation and exit, anonymity of responses, and protection of participants' interests were observed at all times.

\section{Presentation of Results}

The responses from all the respondents were carefully documented and arranged using Atlas.ti. The analysis of the results are presented in Figure 3 showing that the following factors contribute to the challenges in the strategy implementation process at SAPO: poor strategic plans, lack of clarity about the strategic plans, poorly defined 
strategic implementation processes, lack of ownership of strategic implementation, lack of proper communication systems, lack of resources/equipment issues, staff shortages, lack of performance tracking and monitoring system, lack of financial resources, lack of proper information and feedback system, lack of proper infrastructure, poor leadership, stock problems, low salaries, system problems and complaints from consumers.

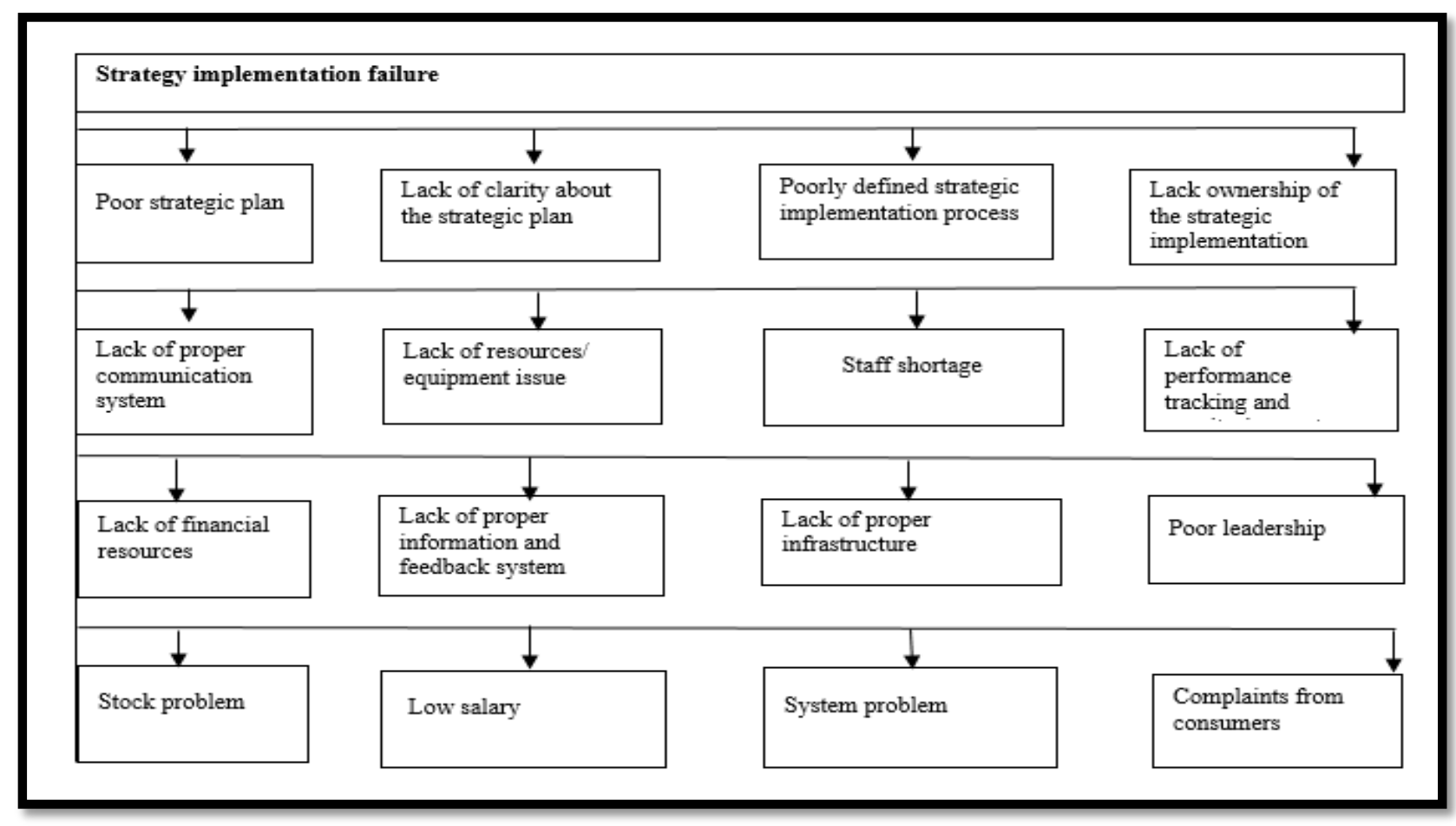

Figure 3. Responses from participants on challenges in strategy implementation by SAPO

\section{Discussion of Results}

Concerning challenges to the strategic implementation of service quality with managers and frontline employees, both managers and frontline employees in this study indicated similar challenges. The interpretation of the results of this paper was performed with a comprehensive approach. The participants of this study highlighted that poor strategic plans do not enable them to implement the post office strategic plan correctly. In this regard, frontline employees lack clarity about the strategic plan that is been formulated by top management. As such, it becomes difficult for them to implement it. This affects them on a daily basis. Kaplan and Norton (2008) noted that the implementation of plans should be clear and should be communicated to employees by management to enhance strategy implementation. The participants affirmed that resources and equipment issues constituted a challenge in executing their major duties due to the inability to allocate adequate funding to the strategy implementation process. This result conforms with the findings of Ehlers and Lazenby (2010) and Cogin et al. (2016), who noted that the incapability to place human and financial resources in the right position inhibits an organisation in accomplishing its overall objectives. With regard to infrastructure and system problems, participants indicated that the state of infrastructure in post offices constitute challenges in the strategy implementation process. Further probing revealed that some post office employees lacked the ability to handle complaints from consumers, which frustrate the implementation of strategies. This is, however, linked to the people barrier, leadership and managerial issues. Bryson (2018) asserts that organisations should work as a team to implement essential procedures to reinforce the capacity of the organisation. It is deduced from the responses that postal employees need an increase in salary for effective strategy implementation. Snelgar et al. (2013) affirm that a key factor to employee commitment within service organisations is remuneration. Nujjoo and Meyer (2012) also confirm that all South African organisations should recognize the value of intrinsic rewards within their reward management strategies.

Participants indicated that SAPO experiences staff shortages and this causes increasing workload for staff, which then causes a delay in giving quality service besides increasing mistakes. This affirm with previous research that has 
identified staff shortage as a significant predictor of organisational performance (Shaw et al., 2005; Meier \& Hicklin, 2008; Boyne et al., 2011; Hur, 2013). When there is a shortage of staff the responsibilities and workload of staff increase, which leads to mistakes and other inefficiencies, and negatively effects individual performance, client care, and ultimately organisational performance.

Participants indicated that post office management lack the capacity to implement plans to achieve service delivery, which is linked to leadership issues, management barriers, lack of ownership and commitment to strategic implementation. This conforms with the research conducted by Ndambiri (2015), who investigated the barriers encountered in the execution of a strategy where two factors often hinder the implementation of a formulated strategy, namely: the organisation's vision and an organisation's business process. Concerning vision, it is stated that there is often a problem linking an organisation's vision to the strategy. This indicates that management have a problem linking what needs to be done with where they want to go. This happens when managers are unable to envisage the bigger picture concerning strategy, structures, and processes. This also happens when the people involved in strategy implementation do not understand the vision. The missing of targets brings about disconnect often found in the vision, the strategies, and objectives. The business processes include the structures and the programmes that are designed to facilitate the operation of an organisation such as the control systems, reward and disciplinary systems, resource distribution and structures.

\section{Recommendations to Managers and Frontline Employees}

The following recommendations are made to facilitate effective strategy implementation in the South Africa Post Office in the North West province.

To managers and frontline employees who need to ensure postal consumers received effective service delivery:

- This study established that management should include frontline staff in the organisation's strategic planning meetings since they are in direct contact with consumers and are in a better position to advise management on the strategies to improve service quality. Thus, it is clear that, if frontline employees are involved in the strategic planning meetings, it makes it easier for them to understand and implement the strategic plan effectively in order to help achieve the post office overall objectives. Also, management needs to employ more staff, improve on the networking systems and also create a channel to inform customers about recent changes that come up all the time in order to always keep its consumers satisfied and establish an effective information and feedback system. And finally, SAPO management should open more training centres and employ training experts, enabling employees to gain regular training, preferably at the same time as when they are performing their normal duties.

- It is recommended that post office management needs to provide staff members with all the available resources needed, such as materials and equipment, and an effective operating system that do not fail employees who are tasked with giving quality services to members of the public, good infrastructure to enhance the strategy implementation process, advanced communication procedures should be held in great respect in all the post offices and postal security, as well as a good working environment.

- The implementation of the strategic plan in post offices is a persistent challenge, and this fails management to reach their strategic ambitions. It is recommended that post office management should pay more attention to the implementation of their strategic plan, by providing the necessary resources needed to implement the strategic plan effectively. Finally, this study recommends that managers and frontline employees should have similar expectations and perceptions towards the post office's service quality as this study found that employees thoughts do differ from that of managers. This will be made possible by having a strategic orientation philosophy in the post office.

\section{Conclusion}

This study explored the challenges in strategy implementation towards achieving effective service delivery by South African Post Offices (SAPO) in the North West province. This study was motivated by the continuous decline in postal consumers, mail volume and revenues as recorded by post offices. This study focused on the post office managers and frontline employees of SAPO who have vast experience in the implementation of strategies to achieve service quality. It was noted that challenges in strategy implementation are influenced by both internal and external factors, which are fundamentally related to the post office management, managers and frontline employees and governmental matters. The contingency theory was proposed to the post office managers, challenging managers to adopt the best tactics to handle different organisational situations. Also, it was noted that achieving effective strategy implementation involves the collaboration of post office managers, frontline employees, and consumers to discharge their responsibilities in order to reach organisational objectives, and consumer satisfaction. Post office managers and 
frontline employees could enhance strategy implementation by integrating the recommendations of this study into their various administrative practices in an endeavor to achieve service quality to all postal consumers.

This study was limited to only the North West province, and the findings may not be practically generalizable due to the differences in the management capabilities of post offices in other provinces of South Africa. This study only investigated challenges in strategy implementation towards achieving effective service delivery by South African Post Offices (SAPO) in the North West province and did not include all post offices in the other province in South Africa, due to non-availability of sufficient material and financial constraints on the subject of research, as well as very little research on strategic management of service quality in postal sectors of South Africa resulting in only few local previous studies to benchmark this study. Research should be conducted in other province in South Africa post offices to get the views of challenges to strategic implementation of managers and frontline employees on service quality. The researcher further proposes that periodic research studies on the impact on the strategic management skills on managers and frontline employees on service quality in the postal sector in other province in South Africa and the private sector could be conducted in the future. Furthermore, research should be conducted to develop a framework that would update the flow of information in the postal sector to obtain reliable information to be used in informing managers, staff as well as postal customers on new and updating postal information within postal branches.

\section{References}

Ackermann, F., \& Eden, C. (2013). Strategic management of stakeholders: theory and practice. Long Range Planning, 4(6), 179-196.

Afonina, A. (2015). Strategic management tools and techniques and organisational performance: findings from Czech Republic. Journal of Competitiveness, 7(5), 19-36. https://doi.org/10.7441/joc.2015.03.02

Ahimbisibwe, A., Cavana, R. Y., \& Daellenbach, U. (2015). A contingency fit model of critical success factors for software development projects. Journal of Enterprise Information Management, 28(1), 7-33.

Alexander, L. D. (1991). Strategy implementation: nature of the problem. International Review of Strategic Management, 2(1), 73-91.

Ansoff, H. I., Kipley, D., Lewis, A. O., Helm-Stevens, R., \& Ansoff, R. (2018). Implanting strategic management. Switzerland: Springer.

Auditor-General South Africa. (2017). Auditor-General's report. Retrieved 20th May 2018, from http://www.agsa.co.za/Reporting/MFMAReports/ MFMA2016-2017.aspx

Auditor-General South Africa. (2018/19-2020). Auditor-General's report. Retrieved 20th 2020, from http://www.agsa.co.za/Reporting/MFMAReports/ MFMA2016-2017.aspx

Bamberger, P. A., Biron, M., \& Meshoulam, I. (2014). Human resource strategy: Formulation, implementation, and impact. New York, NY: Routledge. https://doi.org/10.4324/9780203075838

Barrick, M. R., Thurgood, G. R., Smith, T. A., \& Courtright, S. H. (2015). Collective organisational engagement: Linking motivational antecedents, strategic implementation, and firm performance. Academy of Management Journal, 58(1), 111-135. https://doi.org/10.5465/amj.2013.0227

Barton, L. C., \& Ambrosini, V. (2013). The moderating effect of organisational change cynicism on middle manager strategy commitment. The International Journal of Human Resource Management, 24(4), 721-746.

Baum, W. M. (2016). Understanding behaviorism: Behavior, culture, and evolution. New Jersey, NJ: John Wiley \& Sons.

Beer, M. (2013). The strategic fitness process: A collaborative action research method for developing and understanding organisational prototypes and dynamic capabilities. Journal of Organisation Design, 2(1), 27-33.

Boyne, G. A., James, O., John, P., \& Petrovsky, N. (2011). Top management turnover and organizational performance: A test of a contingency model. Public Administration Review, 71(4), 572-581.

Brinkschröder, N. (2014). Strategy implementation: Key factors, challenges and solutions. Twente: Bacchelor's thesis, Twente University.

Bryson, J. M. (2018). Strategic planning for public and nonprofit organisations: A guide to strengthening and sustaining organisational achievement (5th ed.). New Jersey, NJ: John Wiley \& Sons.

Candido, C., \& Santos, S. P. D. (2015). Strategy implementation: What is the failure rate?. Journal of Management \& Organisation, 21(2), 237-262. https://doi.org/10.1017/jmo.2014.77 
Cogin, J. A., Ng, J. L., \& Lee, I. (2016). Controlling healthcare professionals: how human resource management influences job attitudes and operational efficiency. Human Resources for Health, 14(1), 1-8.

DuBrin, A. J. (2011). Essentials of management. Boston: Cengage Learning.

Ehlers, T., \& Lazenby, K. (2010). Strategic management: South African concepts and cases (3rd ed.). Pretoria: Van Schaik.

Eustace, A., \& Martins, N. (2014). The role of leadership in shaping organisational climate: An example from the fast moving consumer goods industry. SA Journal of Industrial Psychology, 40(1), 1-14.

Fiedler, F. R. E. D. (2015). Contingency theory of leadership. Organisational behavior: Essential theories of motivation and leadership. New York: Routledge Publishers.

Flynn, B., Hou, B., \& Zhao, X. (2009). The impact of supply chain integration on performance: a contingency and configuration approach. Journal of Operations Management, 28(1), 58-71.

Girma, S. (2016). The relationship between leadership style, job satisfaction and culture of the organisation. International Journal of Applied Research, 2(4), 35-45.

Goldkuhl, G. (2012). Pragmatism vs interpretivism in qualitative information systems research. European Journal of Information Systems, 21(2), 135-146. https://doi.org/10.1057/ejis.2011.54

Hellriegel, D., Jackson, S. E., Slocum, J., Staude, G., Amos, T., Klloper, H. B., ... Oosthuizen, T. (2008). Management (3rd ed.). SA: Oxford University Press Southern Africa. (Pty) Ltd.

Hornstein, H. A. (2015). The integration of project management and organisational change management is now a necessity. International Journal of Project Management, 33(2), 291-298.

Hur, Y. (2013). Turnover, voluntary turnover, and organisational performance: Evidence from municipal police departments. Public Administration Quarterly, 37(1), 3-35.

Jarzabkowski, P., \& Kaplan, S. (2015). Strategy tools-in-use: A framework for understanding "technologies of rationality" in practice. Strategic Management Journal, 36(4), 537-558. https://doi.org/10.1002/smj.2270

Jelenc, L. (2009). Review of theories in strategic management field-toward the creation of schools of strategic management. The Business Review Cambridge, 14(1), 240-247.

Jenkins, W., \& Williamson, D. (2016). Strategic management and business analysis. Abingdon: Routledge.

Johnson, G., Scholes, K., \& Whittington, R. (2008). Exploring Corporate Strategy. Text and Jossey Bass, 7(1), 21-44.

Jones, D. R. (2010). Leadership strategies for sustainable development: A case study of Suma Wholefoods. Business Strategy and the Environment, 9(1), 378-389.

Jones, G. R., \& Hill, C. W. L. (2014). Theory of strategic management. London: Cengage Learning.

Joyce, P. (2017). Strategic leadership in the public sector (2nd ed.). New York: Routledge Publishers.

Kaplan, R. S., \& Norton, D. P. (2008). The execution premium. Massachusetts: Harvard Business School Publishing.

Klettner, A. L. (2014). Corporate governance regulation: assessing the effectiveness of soft law in relation to the contemporary role of the board of directors. Doctoral dissertation.

Knott, E. (2016). The effect of talent management practices on employee performance among real estate companies in Kenya: A case of suraya property group limited. Doctoral dissertation, United States International University-Africa.

Koschmann, M. (2012). What is organisational communication?. Retrieved 25th April 2017, from http://koschmann.webstarts.com/uploads/what_is_organizational_communication.pdf

Mapetere, D., Mavhiki, S., Nyamwanza, T., Sikomwe, S., \& Mhonde, C. (2012). Strategic role of leadership in strategy implementation in Zimbabwe's state-owned enterprises. International Journal of Business and Social Science, 3(16), 270-278.

Maree, K. (2010). First steps in research. Fifth impression. Pretoria: Van Schaik Publishers.

Maroa, J. G., \& Muturi, W. (2015). Influence of strategic management practices on performance of floriculture firms in Kenya: A survey of Kiambu County, Kenya. International Journal of Economics, Commerce and Management, 3(7), 497-513.

Marx, L. (2010). Technology: The emergence of a hazardous concept. The Society for the History of Technology, 51(4), 561-577. 
Mathore, J. (2016). Effect of strategy implementation on organisation performance: A case study of diamond trust bank. Doctoral dissertation, University of Nairobi.

Meier, K. J., \& Hicklin, A. (2008). Employee turnover and organizational performance: Testing a hypothesis from classical public administration. Journal of Public Administration Research \& Theory, 18(4), 73-590.

Meyer, D. S. (2016). Thinking about strategy. Strategies for Social Change, 1(1), 3-22.

Miller, R., Williams, I., Allen, K., \& Glasby, J. (2013). Evidence, insight, or intuition? Investment decisions in the commissioning of prevention services for older people. Journal of Care Services Management, 7(4), 119-127. https://doi.org/10.1179/1750168714Y.0000000027

Mitchell, S. (2015). Top problems leaders face in the workplace and an innovative way to overcome them. Retrieved May 2, 2019, from https://www.linkedin.com/pulse/top-problems-leaders-face-workplace-innovative-waythem-mitchell

Musikavanhu, G. M. (2017). A service quality framework for the Botswana hospitality sector. Doctoral dissertation, North-West University South Africa.

Ndambiri, S. (2015). Barriers of effective strategy execution: Organisation's challenge. The International Journal of Business \& Management, 3(9), 296-298.

Ndolloh, K. O. (2016). Response strategies adopted by co-operative insurance company (Cic) group limited to changes in the external environment. Doctoral dissertation, University of Nairobi.

Ndung'u, A. (2016). Influence of strategic management practices on the performance of Christian churches in Nairobi, Kenya. Doctoral dissertation, University of Nairobi.

Neumann, R. (2014). Making political ecology. Boston: Routledge. https://doi.org/10.4324/9780203764206

Njihia, N. N. (2009). Strategic Responses of Kenya Commercial Bank Limited to Changes in Kenyan Banking Industry. Master Dissertation, University of Nairobi: Unpublished MBA Project.

Nujjoo, A., \& Meyer, I. (2012). The relative importance of different types of rewards for employee motivation and commitment in South Africa. South African Journal of Human Resource Management, 10(2), 1-10. https://doi.org/10.4102/sajhrm.v10i2.442

O’Donnell, O., \& Boyle, R. (2008). Understanding and managing organisational culture. Dublin, Ireland: Institute of Public Administration.

Ohaegbu, A. V., \& Agwu, P. E. (2015). Strategic management of the benefits and challenges of HR outsourcing in effective organisational management. Journal of Business Studies Quarterly, 7(2), 89-99.

Olson, E. (2017). Strategic implementation. Retrieved July 20, 2019, from https://onstrategyhq.com/resources/strategicimplementation/

Pearce, J. A., \& Robinson, R. B. (2013). Strategic management: Formulation, implementation, and control. New York, NY: Irwin/McGraw-Hill.

Pollack, J., \& Pollack, R. (2015). Using Kotter's eight stage process to manage an organisational change program: Presentation and practice. Systemic Practice and Action Research, 28(1), 51-66. https://doi.org/10.1007/s11213-014-9317-0

Radomska, J. (2015). The role of managers in effective strategy implementation. International Journal of Contemporary Management, 13(3), 77-85.

Rahi, S. (2017). Research design and methods: A systematic review of research paradigms, sampling issues and instruments development. International Journal of Economics \& Management Sciences, 6(2), 1-5.

Rajasekar, J. (2014). Factors affecting effective strategy implementation in a service industry: a study of electricity distribution companies in the sultanate of Oman. International Journal of Business and Social Sciences, 5(9), 169-183.

Rouleau, L., \& Balogun, J. (2011). Middle managers, strategic sense making, and discursive competence. Journal of Management Studies, 48(5), 1-31. https://doi.org/10.1111/j.1467-6486.2010.00941.x

Sauser, B. J., Reilly, R. R., \& Shenhar, A. J. (2009). Why projects fail? How contingency theory can provide new insights-A comparative analysis of NASA's Mars Climate Orbiter loss. International Journal of Project Management, 27(7), 665-679. https://doi.org/10.1016/j.ijproman.2009.01.004

Schoech, D. (2006). Contingency Theory. Retrieved 18th April 2019, from https://wweb.uta.edu/projects/sswtech/6371/coursepack/theory-contingency.pdf 
Shaw, J. D., Gupta, N., \& Delery, J. E. (2005). Alternative conceptualizations of the relationship between voluntary turnover and organizational performance. Academy of Management Journal, 48(1), 50-68.

Shu, C. Y. (2015). The impact of intrinsic motivation on the effectiveness of leadership style towards on work engagement. Contemporary Management Research, 11(4), 327-350. https://doi.org/10.7903/cmr.14043

Siddique, M. I., \& Shadbolt, N. (2016). Strategy implementation: Literature review. Retrieved 26 February 2020, from http://www.onefarm.ac.nz/system/files/resource_downloads/Strategy\%20Implementation\%20Literature\%20Rev iew\%20Final\%20_0.pdf

Sikora, D. M., \& Ferris, G. R. (2014). Strategic human resource practice implementation: The critical role of line management. Human Resource Management Review, 24(3), 271-281. https://doi.org/10.1016/j.hrmr.2014.03.008

Snelgar, R. J., Renard, M., \& Venter, D. (2013). An empirical study of the reward preferences of South African employees. SA Journal of Human Resource Management, 11(1), 1-14. https://doi.org/10.4102/sajhrm.v11i1.351

South Africa Auditor-General Report. (2014). Annual Report 2014. Pretoria. Retrieved 10 November 2019, from http://www.agsa.co.za/Portals/1/Audit\%20Reports/Annual\%20Reports/Annual\%20rep

South African Post Office. (2015/2016). Integrated annual report 2015. Retrieved 3 February 2020, from http://www.postoffice.co.za/group/aboutus/annualreport/PostOfficeannualreport2012.pdf

South African Post Office. (2018-20120). Strategic corporate plan. Retrieved 18 July, from https://static.pmg.org.za/150505SAPO_CorporateStrategic_Plan_Final.pdf

Strydom, J. D. (2016). Sharemilking as an alternative business model for the successful establishment of black commercial dairy farmers in South Africa. Doctoral dissertation, University of Pretoria.

Thanyawatpornkul, R., Siengthai, S., \& Johri, L. (2016). Employee's perspective towards strategy execution in facility management in Thailand. Facilities, 34(11), 682-702. https://doi.org/10.1108/F-09-2014-0071

Thornton, L. F. (2013). Dealing with complexities in leadership. Retrieved January 11, 2019, from https://leadingincontext.com/2013/02/27/dealing-with-complexity-in-leadership/

Ungerer, M., Ungerer, G., \& Herhodt, J. (2015). Crystalising the strategic business landscape. London: KR Publishers.

Verweire, K. (2014). Strategy implementation. London and New York, NY: Routledge. https://doi.org/10.4324/9781315849447

Wahab, A. S., Rose, R. C., \& Osman, S. I. W. (2012). Defining the concepts of technology transfer: A literature analysis. International Business Research, 5(1), 61-71.

Wells, R. B. (2011). Weaver's model of communication and its implications. Retrieved May 3, 2019, from http://www.mrc.uidaho.edu/ rwells/techdocs/Weavers\%20Model $\% 20$ of $\% 20$ Communication $\% 20$ and $\% 20$ Its $\% 2$ OImplications.pdf

Yuen, K. F., \& Lim, J. M. (2016). Barriers to the implementation of strategic corporate social responsibility in shipping. The Asian Journal of Shipping and Logistics, 32(1), 49-57. https://doi.org/10.1016/j.ajsl.2016.03.006

Zimmermann, K. A. (2015). What is culture? Definition of culture. Retrieved May 3, 2019, from http://www.livescience.com/21478-what-is-culture-definition-of-culture.html

\section{Copyrights}

Copyright for this article is retained by the author(s), with first publication rights granted to the journal.

This is an open-access article distributed under the terms and conditions of the Creative Commons Attribution license (http://creativecommons.org/licenses/by/4.0/). 